\title{
1 Does circadian regulation lead to optimal gas exchange
}

\section{2 regulation?}

4 Víctor Resco de Dios ${ }^{*}$ a, , Arthur Gessler ${ }^{\text {c d }}$, Juan Pedro Ferrio ${ }^{\text {b }}$, Josu G

5 Alday $^{\mathrm{b}}$, Michael Bahn ${ }^{\mathrm{e}}$, Jorge del Castillo ${ }^{\mathrm{b}}$, Sébastien Devidal ${ }^{\mathrm{f}}$, Sonia

6 García-Muñoz $^{\mathrm{g}}$, Zachary Kayler ${ }^{\mathrm{d}}$, Damien Landais ${ }^{\mathrm{f}}$, Paula Martín-

7 Gómez $^{\text {b }}$, Alexandru Milcu ${ }^{\text {fh }}$, Clément Piel ${ }^{\mathrm{f}}$, Karin Pirhofer-Walzl ${ }^{\mathrm{d}}$,

8 Olivier Ravel ${ }^{\mathrm{f}}$, Serajis Salekin ${ }^{\mathrm{i}}$, David T Tissue ${ }^{\mathrm{a}}$, Mark G Tjoelker ${ }^{\mathrm{a}}$,

9 Jordi Voltas ${ }^{b}$, Jacques Roy ${ }^{\mathrm{f}}$

$11{ }^{a}$ Hawkesbury Institute for the Environment, Western Sydney University, Richmond,

12 Australia.

$13{ }^{\mathrm{b}}$ Department of Crop and Forest Sciences-AGROTECNIO Center, Universitat de

14 Lleida, Lleida, Spain.

$15{ }^{\mathrm{c}}$ Swiss Federal Institute for Forest, Snow and Landscape Research WSL Long-term

16 Forest Ecosystem Research (LWF), Birmensdorf, Switzerland.

17 d Institute for Landscape Biogeochemistry, Leibniz-Centre for Agricultural Landscape

18 Research (ZALF), Müncheberg, Germany.

$19{ }^{\mathrm{e}}$ Institute of Ecology, University of Innsbruck, Innsbruck, Austria.

$20 \quad{ }^{\mathrm{f}}$ Ecotron Européen de Montpellier, CNRS, Montferrier-sur-Lez, France.

21 gIMIDRA, Finca “El Encín”, Alcalá de Henares, Madrid, Spain.

$22{ }^{\mathrm{h}}$ CNRS, Centre d'Ecologie Fonctionnelle et Evolutive Montpellier, France 

available under aCC-BY 4.0 International license.

$23 \quad{ }^{i}$ Erasmus Mundus Master on Mediterranean Forestry and Natural Resources

24 Management, Universitat de Lleida, Lleida, Spain.

$25{ }^{*}$ Corresponding author: Víctor Resco de Dios, Department of Crop and Forest

26 Sciences-AGROTECNIO Center, Universitat de Lleida, E 25198 Lleida, Spain.

27 v.rescodedios@gmail.com

28

29 Running headline: Optimal stomata and the circadian clock

30 


\section{Summary}

32 Optimal stomatal theory is an evolutionary model proposing that leaves trade-off

33 Carbon $(\mathrm{C})$ for water to maximise $\mathrm{C}$ assimilation $(A)$ and minimise transpiration $(E)$,

34 thereby generating a marginal water cost of carbon gain $(\lambda)$ that remains constant over

35 short temporal scales. The circadian clock is a molecular timer of metabolism that

36 controls $A$ and stomatal conductance $\left(g_{\mathrm{s}}\right)$, amongst other processes, in a broad array of

37 plant species. Here, we test whether circadian regulation contributes towards

38 achieving optimal stomatal behaviour. We subjected bean (Phaseolus vulgaris) and

39 cotton (Gossypium hirsutum) canopies to fixed, continuous environmental conditions

40 of photosynthetically active radiation, temperature and vapour pressure deficit over 48

41 hours. We observed a significant and self-sustained circadian oscillation in $A$ and in

42 stomatal conductance $\left(g_{\mathrm{s}}\right)$ which also led to a circadian oscillation in $\lambda$. The lack of

43 constant marginal water cost indicates that circadian regulation does not directly lead

44 to optimal stomatal behaviour. However, the temporal pattern in gas exchange,

45 indicative of either maximizing $A$ or of minimizing $E$, depending upon time of day,

46 indicates that circadian regulation could contribute towards optimizing stomatal

47 responses. More broadly, our results add to the emerging field of plant circadian

48 ecology and show that molecular controls may partially explain leaf-level patterns

49 observed in the field.

51 Key-words: bean, cotton, ecological strategies, gas exchange, leaf, molecular

52 regulation, photosynthesis. 


\section{Introduction}

55 Early trade-offs in ecology recognized the need to balance growth and survival

56 (Grubb 2015). Intense resource acquisition to sustain elevated growth rates, for

57 instance, could lead to quick resource depletion and ultimately death. As a partial

58 explanation for plant response to this constraint, the hypothesis of optimization in

59 stomatal conductance was developed (Cowan 1977; Cowan \& Farquhar 1977). In

60 short, the optimal stomatal conductance hypothesis proposes that stomata balance the

61 trade-off between $A$ (C assimilation) and $E$ (water losses) by maintaining a constant

62 marginal water cost $\left(\lambda=\delta E / \delta A\right.$; in $\left.\mathrm{mol} \mathrm{CO}_{2} \mathrm{~mol}^{-1} \mathrm{H}_{2} \mathrm{O}\right)$, at least over short time

63 scales, at the point where $A$ is maximized and $E$ minimized (Cowan \& Farquhar

64 1977).

65 This optimal strategy was originally postulated as a conservative strategy for

66 plants facing variation in a physical environment that, to a degree, is unpredictable or

67 stochastic. As a result, most tests of the prediction of constant $\lambda$ have been performed

68 under changing vapour pressure deficit, soil water, temperature or $\left[\mathrm{CO}_{2}\right]($ Manzoni et

69 al. 2011; Duursma et al. 2013; Buckley et al. 2014). However, there is also a degree

70 of predictability in the variation observed in the natural environment. Chief amongst

71 these is photoperiod, which varies deterministically as a function of day of year and of

72 geographic location. A nearly universal adaptation to the photoperiod, and other

73 predictable environmental cues, is the endogenous circadian clock (McClung 2006;

74 Resco, Hartwell \& Hall 2009).

75 Circadian rhythms regulate the transcription of $\sim 30 \%$ of the plant's genome

76 (Covington et al. 2008) and, amongst others, diurnal patterns of stomatal conductance

77 and photosynthesis are partially products of circadian regulation (Hennessey, Freeden

78 \& Field 1993; Mencuccini, Mambelli \& Comstock 2000). It has been shown that 
79 resonance between circadian rhythms in gas exchange and environmental cues

80 increases plant growth (Graf et al. 2010; de Montaigu et al. 2015; Kolling et al. 2015;

81 Resco de Dios et al. 2016), and that circadian timing is related to photosynthesis rates

82 and stomatal conductance (Edwards et al. 2011). Regarding the hypothesis of optimal

83 stomatal regulation, Cowan (1982) states that "if diurnal variation in natural physical

84 environment were regular and predictable, then optimization would require only that

85 there be an appropriate circadian rhythm in stomatal aperture". Given that variation in

86 the physical environment is not entirely regular and predictable, here we seek to

87 understand the potential role of circadian rhythms towards optimizing the trade-off in

$88 A$ vs $E$.

89 Circadian biologists often mention circadian regulation as an important

90 component of achieving optimal stomatal conductance (Hubbard \& Webb 2015).

91 However, we are unaware of any direct tests for optimality resulting from circadian

92 regulation, and perhaps the word optimal in those studies is used in general terms, and

93 not in relation to the specific hypothesis of time-invariant $\lambda$. In fact, circadian

94 regulation in $A$ has been documented to be uncoupled and independent from circadian

95 regulation in $g_{\mathrm{s}}$ (Dodd, Parkinson \& Webb 2004), but linkages between these two

96 processes is a pre-requisite for optimal water use. Therefore, if circadian rhythms

97 regulate $A$ and $g_{\mathrm{s}}$ independently from each other, one would hypothesize that

98 circadian regulation alone, would not lead to optimal stomatal regulation.

99 Nonetheless, there is some evidence from theoretical modeling that circadian

100 rhythms could aid in reaching optimality. Circadian regulation serves to "anticipate"

101 predictable environmental cues, in such a way that stomata can adjust in advance

102 ("stomatal priming", Resco de Dios et al. 2016). As such, the clock has been

103 hypothesized to aid in attaining optimality through stomatal priming because direct 
104 responses to regular diurnal fluctuations alone would inevitably lead to a lagged

105 response (Dietze 2014). In other words, stomata show a lagged response to the

106 environment (Vico et al. 2011) and, although it is not expected that optimality

107 operates at every instant, circadian regulation could help in achieving optimality by

108 diminishing the lags through stomatal priming (Dietze 2014).

109 Here, we propose that circadian regulation, per se, does not lead to optimal

110 behavior over diurnal cycles, but that it might help in achieving optimality within

111 field settings. More explicitly, we hypothesize that: 1) because the circadian clock

112 regulates $A$ and $g_{\mathrm{s}}$ independently, circadian action will lead to a time-changing $\lambda$,

113 consistent with non-optimal behavior; 2) the temporal pattern of circadian driven gas

114 exchange will be consistent with a stomatal priming that prepares for regular

115 environmental variation.

116 Assessing the effects of circadian regulation on daytime $A$ and $g_{\mathrm{s}}$ under natural

117 conditions is difficult because the influence of environmental drivers generally mask

118 circadian regulation. Circadian regulation is most strongly expressed under a

119 "constant environment": when temperature, radiation, vapour pressure deficit and

120 other environmental drivers are held experimentally constant over $24 \mathrm{~h}$ or longer.

121 Therefore, we addressed our questions by examining temporal variation in $\lambda$ in an

122 herb (bean, Phaseolus vulgaris) and in a shrub (cotton, Gossypium hirsutum) under

$12348 \mathrm{~h}$ of constant environmental conditions.

124 It has been noted that the optimal stomatal hypothesis cannot be tested directly

125 with experimental manipulations such as $48 \mathrm{~h}$ of constant environmental conditions,

126 because optimal stomatal theory represents an evolutionary process and therefore can

127 only be assessed under environmental conditions observed during their evolution

128 (Cowan 2002). However, tests of the optimal stomatal hypothesis have been 
129 successfully conducted in elevated $\mathrm{CO}_{2}$ enrichment experiments (Barton et al. 2012;

130 Medlyn et al. 2013), although it is clear that plants have not evolved experiencing 131 step-function, large sudden increases in $\mathrm{CO}_{2}$ concentration (Woodward 2007). We

132 suggest that our experimental approach is somewhat similar to other approaches,

133 except that to avoid the potential for experimental artefacts, we do not test whether the

134 optimal stomatal theory is observed under constant environmental conditions. Instead,

135 our goal is to assess the potential for circadian regulation to contribute to optimal

136 stomatal behaviour in natural, varying environments.

137 Throughout the manuscript, we will present data on both the marginal water

138 cost of carbon gain $(\lambda=\delta E / \delta A)$ and on $A_{\text {net }} / g_{\text {s }}$ (intrinsic water use efficiency). This is

139 for the sake of clarity as $A_{\text {net }} / g_{\mathrm{s}}$ is more often used than the marginal water cost of

140 carbon gain, and also because those two variables tend to be inversely correlated

141 (using the convention of this manuscript, see methods for calculation of $\lambda$ ). However,

142 it is important to note that $\lambda$ is not simply the inverse of water use efficiency $(A / E)$

143 because $\lambda$ is a partial derivative, i.e. an expression of the co-variation between the two

144 variables for a given level of $g_{\mathrm{s}}$ (see for instance (Thomas, Eamus \& Bell 1999) for

145 different methods of calculation).

147 Materials and methods

148 Experimental set-up

149 The experiment was performed at the Macrocosms platform of the Montpellier

150 European Ecotron, Centre National de la Recherche Scientifique (CNRS, France). We

151 used 6 controlled-environment units of the macrocosms platform ( 3 planted with bean

152 and 3 with cotton), where the main abiotic (air temperature, humidity and $\mathrm{CO}_{2}$

153 concentration) drivers were automatically controlled. The soil was extracted using 
154 large lysimeters $\left(2 \mathrm{~m}^{2}\right.$, circular with a diameter of $1.6 \mathrm{~m}$, weighing 7 to 8 tonnes) from

155 the flood plain of the Saale River near Jena, Germany, and used in a previous Ecotron

156 experiment on biodiversity (Milcu et al. 2014). After that experiment, the soil was

157 ploughed down to $40 \mathrm{~cm}$ and fertilized with 25/25/35 NPK (MgO, $\mathrm{SO}_{3}$ and other

158 oligoelements were associated in this fertilizer: Engrais bleu universel, BINOR,

159 Fleury-les-Aubrais, FR).

160 The soil was regularly watered to $c a$. field capacity by drip irrigation, although

161 irrigation was stopped during each measurement campaign (few days) to avoid

162 interference with water flux measurements. However, no significant differences (at $P$

$163<0.05$, paired t-test, $\mathrm{n}=3$ ) in leaf water potential occurred between the beginning and

164 end of these measurement campaigns, indicating no apparent effect of a potentially

165 declining soil moisture on leaf hydration.

166 Environmental conditions within the macrocosms (excluding the experimental

167 periods) were set to mimic outdoor conditions, but did include a $10 \%$ light reduction

168 by the macrocosm dome cover (sheet of Fluorinated Ethylene Propylene). During

169 experimental periods, light was controlled by placing a completely opaque fitted

170 cover on each dome to block external light inputs (PVC coated polyester sheet Ferrari

171502 , assembled by IASO, Lleida, Spain), and by using a set of 5 dimmable plasma

172 lamps (GAN 300 LEP with the Luxim STA 41.02 bulb, with a sun-like light

173 spectrum); these lamps were hung $30 \mathrm{~cm}$ above the plant canopy and provided a PAR

174 of $500 \mu \mathrm{mol} \mathrm{m} \mathrm{m}^{-2}$. We measured PAR at canopy level with a quantum sensor (Li-

175 190, LI-COR Biosciences, Lincoln, NE, USA) in each macrocosm.

176 Bean and cotton were planted in 5 different rows within the macrocosms on

$17710^{\text {th }}$ July 2013 , one month before the start of the measurements, and thinned to

178 densities of 10.5 and 9 individuals $\mathrm{m}^{-2}$, respectively. Cotton (STAM-A16 variety by 
179 INRAB/CIRAD) is a perennial shrub with an indeterminate growth habit. This cotton

180 variety grows to $1.5-2 \mathrm{~m}$ tall and has a pyramidal shape and short branches. Bean

181 (recombinant inbred line RIL-115 bred by INRA Eco\&Sol) is an annual herbaceous

182 species. RIL-115 is a fast growing, indeterminate dwarf variety, 0.3-0.5 $\mathrm{m}$ tall; it was

183 inoculated with Rhizobium tropici CIAT 899 also provided by INRA. During the

184 experiment, bean and cotton generally remained at the inflorescence emergence

185 developmental growth stage (codes 51-59 in BBCH scale, the standard phenological

186 scale within the crop industry; Feller et al. 1995; Munger et al. 1998). Further details

187 on Ecotron measurements have been provided elsewhere (Resco de Dios et al. 2015).

188 During each experimental period, plants were entrained for five days under

189 environmental conditions that mimicked the pattern observed in an average August

190 sunny day in Montpellier in terms of $T_{\text {air }}\left(28 / 19^{\circ} \mathrm{C}\right.$, diurnal max/min) and VPD.

191 However, we kept radiation levels much lower (at $500 \mu \mathrm{mol} \mathrm{m} \mathrm{m}^{-2}$ at canopy level)

192 because previous research proposed that stomatal behavior should follow optimal

193 theory when photosynthesis is light- (and not $\mathrm{CO}_{2}$ ) limited (Medlyn et al. 2011), and

194 our PAR values ensured this was the case. After 5 days of entrainment, we maintained

195 environmental conditions constant starting at solar noon and for the next $48 \mathrm{~h}$.

197 Measurements

198 We characterized the general pattern of gas exchange during the last day of

199 entrainment and during constant environmental conditions by monitoring, every 4

200 hours, gas exchange (LI-6400XT, Li-Cor, Lincoln, Nebraska, USA) in three different

201 leaves, within each of the three domes, per species that were available. To diminish

202 redundancy in the presentation, only $A_{\text {net }} / g_{\mathrm{s}}$ will be shown to characterize this general

203 pattern. 
To obtain enough resolution to test for temporal changes in the marginal water

205 cost of carbon gain, we additionally measured gas exchange every 2 minutes by using

206 2-3 additional portable photosynthesis systems per species and day. Each instrument

207 was continuously deployed on a leaf for $24 \mathrm{~h}$, and the Auto-Log function was used.

208 Measurements were conducted over $48 \mathrm{~h}$ with an effective $n=3$ per species (1-2

209 leaves were measured per macrocosm, in a total of 3 macrocosms). To diminish

210 redundancy in the presentation, only $A_{\text {net }}$ and $g_{\mathrm{s}}$ (along with $g_{1}$ ) will be shown from

211 these high-resolution measurements (but not $A_{\text {net }} / g_{\mathrm{s}}$ ).

213 Analyses

214 The marginal water cost used was estimated from parameter $g_{1}$ in the stomatal model

215 of Medlyn et al. (2011). This model was derived from optimal stomatal theory, such

216 that the $g_{1}$ is inversely proportional to the root square of $\lambda$. We calculated the

217 marginal water cost from the Medlyn et al. (2011), and assuming minimal

218 conductance $\left(g_{0}\right)$ was 0 , so that we could compare the variability observed in our

219 experiment with that observed in a recent synthesis reporting $g_{1}$ values for 314 species

220 from 10 different functional types (Lin et al. 2015). We calculated values of $g_{1}$

221 separately for each hour.

222 We examined statistical significance of temporal patterns in $g_{1}$ with a

223 Generalized Additive Mixed Model (GAMM) fitted with automated smoothness

224 selection (Wood 2006) in the R software environment ( $m g c v$ library in R 3.1.2, The $\mathrm{R}$

225 Foundation for Statistical Computing, Vienna, Austria), including macrocosms as a

226 random factor. This approach was chosen because there are no a priori assumptions

227 about the functional relationship between variables. We accounted for temporal

228 autocorrelation in the residuals by adding a first-order autoregressive process structure 
229 (nlme library, Pinheiro \& Bates 2000). Significant temporal variation in the GAMM

230 best-fit line was analysed after computation of the first derivative (the slope, or rate of

231 change) with the finite differences method. We also computed standard errors and a

$23295 \%$ point-wise confidence interval for the first derivative. The trend was

233 subsequently deemed significant when the derivative confidence interval was bounded

234 away from zero at the $95 \%$ level (for full details on this method see Curtis \& Simpson

235 2014). Periods with no significant variation are illustrated on the figures by the yellow

236 line portions, and significant differences occur elsewhere. The magnitude of the range

237 in variation driven by the circadian clock was calculated using GAMM maximum and

238 minimum predicted values.

\section{Results}

241 We observed a self-sustained oscillation in $A_{\text {net }}, g_{\mathrm{s}}$ and $A_{\text {net }} / g_{\mathrm{s}}$ that showed a $\sim 24 \mathrm{~h}$

242 periodicity (Figs. 1, 2, Table 1). That is, there was a significant variation in $A_{\text {net }}$ and $g_{\text {s }}$

243 in the absence of variation in environmental drivers, and this variation showed a

244 diurnal cycle. Although $A_{\text {net }}$ and $g_{\text {s }}$ generally followed the same pattern in that they

245 both concurrently showed either a positive or a negative trend, the magnitude of the

246 oscillation was larger in $g_{\mathrm{s}}(54-84 \%$ change, Table 1$)$, than in $A_{\text {net }}(28-42 \%$ change,

247 Table 1) over a $24 \mathrm{~h}$ cycle in constant environmental conditions. In turn, this led to a

248 significant variation in instantaneous water use efficiency $\left(A_{\text {net }} / g_{\mathrm{s}}\right)$ that was $46-74 \%$ of

249 that during entrainment (Table 1). If we only consider the oscillation during the

250 subjective day (the time under constant conditions when it would have normally been

251 daytime during entrainment) we still observe a significant and time-dependent

252 variation in $A_{\text {net, }}, g_{\mathrm{s}}$ and $A_{\text {net }} / g_{\mathrm{s}}$, although of smaller magnitude than during the whole

25324 h cycle (Figs. 1, 2). 
255 subjective afternoon under constant conditions (hours 0-6 in Fig. 2c), it remained

256 constant in the first hours of the night, and then it increased again from the subjective

257 midnight (hour 12 in Fig. 2c) until the following subjective noon (hour 24 in Fig. 2c).

258 The rhythm dampens slightly in the second $24 \mathrm{~h}$ period under constant conditions

259 (hours 24-48), because the clock is flexible and becomes entrained every day

260 (Hennessey \& Field 1991; Graf et al. 2010). However, we can still observe temporal

261 fluctuations similar to those in the previous day (although with a smaller degree of

262 significance). Because this study mostly focused on the implications of clock

263 regulation within field settings, the results during the first day are most important

264 because this reflects the period of highest influence of natural environmental

265 variation.

266 We also observed a diurnal self-sustained cycle in $g_{1}$ (Fig 1). That is, we did

267 not observe homeostasis in the marginal water cost despite lack of variation in

268 environmental drivers. Instead, we observed a pattern that was generally opposite to

269 that found in water use efficiency: $g_{1}$ significantly declined during the subjective

270 afternoon in both species (although with a more pronounced decline in cotton), and a

271 significant increase during the subjective night occurred for both species, that

272 continued into the subjective morning for cotton.

\section{Discussion}

275 The importance of circadian regulation towards achieving optimization

276 We observed a significant and self-sustained $24 \mathrm{~h}$ oscillation in $A_{\text {net }}$ and $g_{\mathrm{s}}$, of

277 different magnitude for each process, and that ultimately led to a diurnal oscillation in

278 intrinsic water use efficiency and in the marginal cost of water, despite the absence of 
variation in environmental drivers. Diurnal variation in $g_{1}$ ranged from 5.5 to 0.5 over

280 the $24 \mathrm{~h}$ cycle, and from 5.5 to 1.7 when we only consider variation during the

281 subjective daytime (Fig. 1). There are many processes that could explain an afternoon

282 decline in $A_{\text {net }}$, including feedback inhibition from starch accumulation,

283 photorespiration and stomatal feedbacks, amongst others (Azcón-Bieto 1983; Jones

284 1998; Flexas et al. 2006). Similarly, a multitude of processes could explain the

285 afternoon decline in $g_{\mathrm{s}}$, including hydraulic feedbacks and depletion of stem

286 capacitors (Jones 1998; Zhang et al. 2014). However, the only process that can

287 explain a self-sustained $24 \mathrm{~h}$ cycle is the circadian clock (Resco, Hartwell \& Hall

288 2009). We can therefore conclude that, in the absence of variation in the physical

289 environment, circadian regulation of stomatal behaviour per se does not directly lead

290 to an optimization, because $g_{1}$ was not constant throughout the experiment. However,

291 as we will discuss further below, the pattern of variation in $g_{1}$ indicates that circadian

292 regulation could be an important contributor to achieving optimality in the field.

293 Under the well-watered and fertilized conditions of this experiment, where

294 radiation was probably the only limiting factor, we observed a stronger relative

295 fluctuation in $g_{\mathrm{s}}$ than in $A_{\text {net }}$. This result is consistent with previous studies (Doughty

296 et al. 2006; Yakir et al. 2007) and suggests that stronger clock regulation over $g_{\mathrm{s}}$ than

297 over $A_{\text {net }}$ could be widespread across $C_{3}$ plants. On the one hand, these temporal

298 patterns could be interpreted as an indication that the clock fosters a maximization of

$299 A$ at the time of maximal potential for assimilation ( $A$ peaked at the subjective noon)

300 which, in turn, would be aided by a maximal $g_{\mathrm{s}}$ which decreases diffusional

301 limitations. On the other hand, the stronger decrease in $g_{s}$, relative to that in $A_{\text {net, }}$,

302 during the subjective morning and afternoon, when conditions would have become

303 less favourable for assimilation in a naturally fluctuating environment, is consistent 
304 with a conservative water use strategy. Therefore, this result is consistent with the

305 hypothesis that circadian-driven stomatal priming could contribute towards reaching

306 optimality (Dietze 2014).

Nonetheless, this stomatal regulation strategy contrasts with other work that

308 has shown that circadian regulation tends towards "wasting" water at times when

309 there is no $A$. Circadian regulation is one of the main drivers of the temporal pattern of

310 nocturnal $g_{\text {s }}$, which increases constantly from $c a$. midnight until predawn (Caird,

311 Richards \& Donovan 2007; Resco de Dios et al. 2015). There is no $A$ overnight and,

312 therefore nocturnal water use is not directly linked with assimilation. However,

313 different studies have linked higher predawn $g_{\text {s }}$ with higher $A$ early in the morning

314 (although whether or not this has a significant effect on plant growth is still under

315 discussion, cf. Auchincloss et al. 2014; Resco de Dios et al. 2016). Therefore,

316 compensation could occur if we observe circadian regulation over the full diurnal

317 cycle, where an increase in $A$ at different times (e.g: subjective noon in this study or

318 early morning in the cited work) would be accompanied by higher water losses

319 (maximum $g_{\mathrm{s}}$ at subjective noon, and increase in $g_{\mathrm{s}}$ overnight, respectively); but a

320 more conservative water use occurs at other times (when the relative decline in $g_{\mathrm{s}}$ is

321 higher than in $A$, such as the afternoon or evening).

322 Our study is, to the best of our knowledge, the first to report a circadian

323 pattern in $g_{1}$. As previously mentioned, the optimal stomatal hypothesis does not

324 present specific predictions about what should happen under environmental conditions

325 that do not naturally occur in the field (Cowan 2002). One could argue that $24 \mathrm{~h}$ of

326 continuous light does occur above the Polar circle, but not as a constant light intensity

327 as utilised in our experiment, and moreover, bean and cotton did not evolve in these

328 constant light environments. However, all species experience cloudy days over their 
329 lifespans. Under cloudy days, temporal variation in temperature, vapour pressure

330 deficit and other environmental drivers is generally minimal. Therefore, plants do

331 often experience environmental conditions that are roughly constant for a few hours.

332 It is therefore notable that the largest change in $g_{1}$ occurred in the first 6 hours after

333 conditions were kept constant (1200h to $1800 \mathrm{~h}$ solar time) and this change in $g_{1}$

334 (from 5.5 to 1.7 , see above) was significant. In fact, a recent global synthesis shows

335 that mean $g_{1}$ values across different functional types (in a study encompassing 314

336 species) ranged between 1.6 and 7.2 (Lin et al. 2015). Subsequently, we encourage

337 field studies of leaf-level gas exchange conducted at high temporal resolution to

338 assess the extent of temporal variation in $g_{1}$ under cloudy days.

\section{$340 \quad$ Implications and mechanisms}

341 It has been argued that more biological realism must be incorporated into optimality

342 models to generate a better understanding of optimal behaviour and its constraints

343 (Niinemets 2012). Our results indicate that circadian regulation might be one of the

344 most important processes to be included in these models. For instance, it is well

345 documented that hysteresis in the $E$-VPD relationship generally exists, with higher $E$

346 values in the morning than in the afternoon, at any given VPD. There are different

347 processes that could explain this phenomenon (O'Grady, Eamus \& Hutley 1999;

348 Tuzet, Perrier \& Leuning 2003; Unsworth et al. 2004) and, one of them, is the lag

349 between peaks in radiation and VPD (radiation peaks at solar noon, but VPD peaks a

350 few hours later) (Zhang et al. 2014). Circadian rhythms could contribute to this

351 phenomenon. The clock is often considered to be entrained by both temperature and

352 radiation (Millar 2004). However, the pattern of $A$ and $g_{\mathrm{s}}$ resembles more closely that

353 of radiation, in that both $A$ and $g_{\text {s }}$ peaked at subjective noon, which was the same time 
354 for PAR during entrainment. However, $T_{\text {air }}$ and VPD peaked at $1400 \mathrm{~h}$ during

355 entrainment, and circadian regulation would have already started to decrease stomatal

356 conductance at that time. Therefore, circadian-driven stomatal closure after radiation

357 peaks at noon (which are more pronounced than the decline in $A$ ), in concert with

358 radiation-VPD lags, could be a contributing factor in the documented hysteresis in E-

359 VPD relationships; however, this is not currently accounted for in models.

360 Circadian clocks in plants have traditionally been assumed to be cell

361 autonomous and not coordinated across cells or plant tissues (Endo et al. 2014).

362 However, recent research has observed that a hierarchy exists in plants in that the

363 clock in the leaf vascular tissue regulates the clock in the mesophyll leaf tissue (Endo

364 et al. 2014). Although speculative, it is tempting to hypothesize that clock-controlled

365 hydraulic signals over vascular tissue could also be part of the response driving

366 hysteresis in diurnal transpiration cycles.

367 The effect of circadian regulation on stomatal physiology is still being

368 debated. In Arabidopsis, it has been proposed that the central oscillator of the clock

369 directly controls stomatal behaviour because TOC1 (a component of the central

370 oscillator) regulates ABA signalling (Legnaioli, Cuevas \& Mas 2009). However, other

371 studies have documented that time-dependent circadian regulation of $g_{\mathrm{s}}$ is

372 independent of ABA concentration in beans (Mencuccini, Mambelli \& Comstock

373 2000). Another line of research proposes that it is through $\left[\mathrm{Ca}_{2+}\right]_{\text {cyt }}$ signalling that the

374 circadian clock regulates stomatal movements (Hubbard \& Webb 2015). Circadian

375 regulation of $A$ is relatively better understood, and it involves the joint regulation of

376 the light harvesting complex, the carboxylating enzyme Rubisco, and feedbacks from

377 carbohydrates (Dodd et al. 2014). However, most studies have been conducted at the

378 molecular level with Arabidopsis, and the mechanism of action at "phenotypic" or 
eco-physiological scales, as well as the degree to which processes in Arabidopsis are

380 generalizable to other species, remain unknown.

\section{Conclusions}

383 It has been known for long that the circadian clock could be an important an important component underlying plant fitness. Understanding the reason why the circadian clock is adaptive has proven more challenging. Here we developed the first formal test of the hypothesis that the circadian clock leads towards optimal stomatal regulation and, indeed, the strong stomatal regulation under constant environmental conditions points to the circadian clock as an important component. Although we did not observe a constant marginal water cost under constant conditions, which is necessary for

390 stomatal regulation to be optimal, the optimal stomatal hypothesis would also not 391 have predicted that to occur given the artificiality of the experimental treatment. 392 Importantly, the temporal patterns observed indicate how variation in stomatal 393 regulation was consistent with a circadian-driven stomatal priming that prepares gas 394 exchange in advance of regular environmental fluctuation. Although our experiments 395 were not conducted under conditions typical of field settings, the strong fluctuation in $396 A$ and $g_{\mathrm{s}}$ indicate that circadian regulation could be an important component 397 underlying optimal behaviour in the field. These results add to the emerging field of 398 plant circadian ecology and show that one of the mechanisms by which the circadian 399 clock increases plant fitness is by contributing towards reaching optimal stomatal 400 behaviour. Further studies will need to clarify whether the large changes observed in $401 g_{1}$ under the subjective afternoon also occur in other species and under cloudy 402 conditions. 


\section{Acknowledgements}

405 This study benefited from the CNRS human and technical resources allocated to the

406 ECOTRONS Research Infrastructures as well as from the state allocation

407 'Investissement d'Avenir' AnaEE-France ANR-11-INBS-0001, ExpeER Transnational

408 Access program, Ramón y Cajal fellowships (RYC-2012-10970 to VRD and RYC-

409 2008-02050 to JPF) and internal grants from UWS-HIE to VRD and ZALF to AG.

410 We remain indebted to E. Gerardeau, D. Dessauw, J. Jean, P. Prudent (Aïda CIRAD),

411 C. Pernot (Eco\&Sol INRA), B. Buatois, A. Rocheteau (CEFE CNRS), A. Pra, A.

412 Mokhtar and the full Ecotron team, in particular C. Escape, for outstanding technical

413 assistance during experiment set-up, plant cultivation or subsequent measurements.

414 We also acknowledge R. Duursma, B. Medlyn for comments on an earlier version of

415 this manuscript and to Y.-S. Lin and G.D. Farquhar for useful discussion.

417 Data Accessibility

418 Data are freely accessible upon registration from

419 http://www.ecotron.cnrs.fr/index.php/en/component/users/?view=login.

\section{References}

423 Auchincloss, L., Easlon, H.M., Levine, D., Donovan, L. \& Richards, J.H. (2014) Pre-

424 dawn stomatal opening does not substantially enhance early-morning photosynthesis in Helianthus annuus. Plant Cell and Environment, 37, 13641370.

427 Azcón-Bieto, J. (1983) Inhibition of photosynthesis by carbohydrates in wheat leaves.

$428 \quad$ Plant Physiology, 73, 681-686. 
429 Barton, C.V.M., Duursma, R.A., Medlyn, B.E., Ellsworth, D.S., Eamus, D., Tissue, instantaneous transpiration efficiency at leaf and canopy scales in Eucalyptus saligna. Global Change Biology, 18, 585-595.

434 Buckley, T.N., Martorell, S., Diaz-Espejo, A., Tomas, M. \& Medrano, H. (2014) Is stomatal conductance optimized over both time and space in plant crowns? A field test in grapevine (Vitis vinifera). Plant Cell and Environment, 37, 27072721.

Caird, M.A., Richards, J.H. \& Donovan, L.A. (2007) Nighttime Stomatal growth and development. Genome Biology, 9, R130.

444 Cowan, I.R. (1977) Stomatal behaviour and environment Advances in Botany Research, 4, 117-228.

446 Cowan, I.R. (2002) Fit, Fitter, Fittest; Where Does Optimisation Fit In? Silva Fennica, 36, 745-754.

448 Cowan, I.R. \& Farquhar, G.D. (1977) Stomatal function in relation to leaf metabolism and environment. Integration of Activity in the Higher Plant (ed. D.H. Jennings). Cambridge University Pres, Cambridge.

451 Curtis, C.J. \& Simpson, G.L. (2014) Trends in bulk deposition of acidity in the UK, 286. 
de Montaigu, A., Giakountis, A., Rubin, M., Toth, R., Cremer, F., Sokolova, V., Porri, daily rhythms of gene expression contributes to phenotypic variation. Proceedings of the National Academy of Sciences of the USA, 112, 905-910.

Dietze, M.C. (2014) Gaps in knowledge and data driving uncertainty in models of photosynthesis. Photosynth. Research, 119, 3-14.

Dodd, A.N., Kusakina, J., Hall, A., Gould, P.D. \& Hanaoka, M. (2014) The circadian regulation of photosynthesis. Photosynthesis Research, 119, 181-190.

Dodd, A.N., Parkinson, K. \& Webb, A.A.R. (2004) Independent circadian regulation of assimilation and stomatal conductance in the ztl-1 mutant of Arabidopsis. New Phytologist, 162, 63-70.

Doughty, C., Goulden, M.L., Miller, S. \& da Rocha, H. (2006) Circadian rhythms constrain leaf and canopy gas exchange in an Amazonian forest. Geophysical Research Letters, 33, L15404.

Duursma, R.A., Payton, P., Bange, M.P., Broughton, K.J., Smith, R.A., Medlyn, B.E. \& Tissue, D.T. (2013) Near-optimal response of instantaneous transpiration efficiency to vapour pressure deficit, temperature and [CO2] in cotton

Edwards, C.E., Ewers, B.E., Williams, D.G., Xie, Q., Lou, P., Xu, X., McClung, C.R. \& Weinig, C. (2011) The genetic architecture of ecophysiological and circadian traits in Brassica rapa. Genetics, 189, 375-390. (Gossypium hirsutum L.). Agricultural and Forest Meteorology, 168, 168176.

Endo, M., Shimizu, H., Nohales, M.A., Araki, T. \& Kay, S.A. (2014) Tissue-specific clocks in Arabidopsis show asymmetric coupling. Nature, 515, 419-422. 
478 Feller, C., Bleiholder, H., Buhr, L., Hack, H., Hess, M., Klose, R., Meier, U., Stauss, R., Boom, T.v.d. \& Weber, E. (1995) Phänologische Entwicklungsstadien von Gemüsepflanzen: II. Fruchtgemüse und Hülsenfrüchte. Nachrichtenbl. Deut. Pflanzenschutzd, 47, 217-232.

Flexas, J., Bota, J., Galmes, J., Medrano, H. \& Ribas-Carbo, M. (2006) Keeping a positive carbon balance under adverse conditions: responses of photosynthesis and respiration to water stress. Physiologia Plantarum, 127, 343-352. carbohydrate availability for growth in Arabidopsis plants at night. Proceedings of the National Academy of Sciences of the USA, 107, 9458-9463.

Grubb, P.J. (2015) Trade-offs in interspecific comparisons in plant ecology and how plants overcome proposed constraints. Plant Ecol Divers,

Hennessey, T., Freeden, A. \& Field, C. (1993) Environmental effects on circadian rhythms in photosynthesis and stomatal opening. Planta, 189, 369-376. oscillations in carbon assimilation and stomatal conductance under constant conditions. Plant Physiology, 96, 831-836.

Hubbard, K.E. \& Webb, A.A.R. (2015) Circadian rhythms in stomata: Physiological and molecular aspects. Rhythms in Plants (eds S. Mancuso \& S. Shabala), pp. 231-255. Springer International Publishing Switzerland.

Jones, H. (1998) Stomatal control of photosynthesis and transpiration. Journal of Experimental Botany, 49, 387-398.

501 Kolling, K., Thalmann, M., Muller, A., Jenny, C. \& Zeeman, S.C. (2015) Carbon partitioning in Arabidopsis thaliana is a dynamic process controlled by the 
plants metabolic status and its circadian clock. Plant Cell and Environment,

38, 1965-1979.

Legnaioli, T., Cuevas, J. \& Mas, P. (2009) TOC1 functions as a molecular switch connecting the circadian clock with plant responses to drought. $E M B O$ Journal, 28, 3745-3757.

Lin, Y.-S., Medlyn, B.E., Duursma, R.A., Prentice, I.C., Wang, H., Baig, S., Eamus, water stress: a meta-analysis across plant functional types and climates.

524 McClung, C.R. (2006) Plant Circadian Rhythms. Plant Cell, 18, 792-803.

525 Medlyn, B.E., Duursma, R.A., De Kauwe, M.G. \& Prentice, I.C. (2013) The optimal stomatal response to atmospheric $\mathrm{CO} 2$ concentration: Alternative solutions, 
alternative interpretations. Agricultural and Forest Meteorology, 182-183, 200-203.

Medlyn, B.E., Duursma, R.A., Eamus, D., Ellsworth, D.S., Prentice, I.C., Barton, conductance. Global Change Biology, 17, 2134-2144.

533 Mencuccini, M., Mambelli, S. \& Comstock, J. (2000) Stomatal responsiveness to leaf water status in common bean (Phaseolus vulgaris L.) is a function of time of day. Plant Cell and Environment, 23, 1109-1118.

Milcu, A., Roscher, C., Gessler, A., Bachmann, D., Gockele, A., Guderle, M., Landais, D., Piel, C., Escape, C., Devidal, S., Ravel, O., Buchmann, N., Gleixner, G., Hildebrandt, A. \& Roy, J. (2014) Functional diversity of leaf nitrogen concentrations drives grassland carbon fluxes. Ecology Letters, 17,

543 Munger, L., Bleiholder, H., Hack, H., Hess, M., Stauss, R., Boom, T.v.d. \& Weber, E. 435-444.

Millar, A. (2004) Input signals to the plant circadian clock. Journal of Experimental Botany, 55, 277-283.

547 Niinemets, U. (2012) Optimization of foliage photosynthetic capacity in tree 509. 
550 O'Grady, A.P., Eamus, D. \& Hutley, L.B. (1999) Transpiration increases during the dry season: Patterns of tree water use in eucalypt open-forests of northern Australia. Tree Physiology, 19, 591-597.

Pinheiro, J.C. \& Bates, D.M. (2000) Mixed-Effects Models in S and S-PLUS.

555 Resco de Dios, V., Loik, M.E., Smith, R.A., Aspinwall, M.J. \& Tissue, D.T. (2016)

556 Genetic variation in circadian regulation of nocturnal stomatal conductance enhances plant fitness. Plant Cell and Environment, 39, 3-11.

558 Resco de Dios, V., Roy, J., Ferrio, J.P., Alday, J.G., Landais, D., Milcu, A. \& Gessler, estimating land evapotranspiration Scientific Reports, 5, 10975.

Resco, V., Hartwell, J. \& Hall, A. (2009) Ecological implications of plants' ability to tell the time. Ecology Letters, 12, 583-592.

563 Thomas, D., Eamus, D. \& Bell, D. (1999) Optimization theory of stomatal behaviour. I. A critical evaluation of five methods of calculation. Journal of Experimental Botany, 50, 385-392.

566 Tuzet, A., Perrier, A. \& Leuning, R. (2003) A coupled model of stomatal conductance, photosynthesis and transpiration. Plant, Cell and Environment,

569 Unsworth, M.H., Phillips, N., Link, T., Bond, B.J., Falk, M., Harmon, M.E., Hinckley, T.M., Marks, D. \& U, K.T.P. (2004) Components and controls of water flux in an old-growth Douglas-fir-western hemlock ecosystem. Ecosystems, 7, 468-481. 
573 Vico, G., Manzoni, S., Palmroth, S. \& Katul, G. (2011) Effects of stomatal delays on

574 the economics of leaf gas exchange under intermittent light regimes. New

$575 \quad$ Phytologist, 192, 640-652.

576 Wood, S.N. (2006) Generalized Additive Models: An Introduction. R. Chapman \& Hall/CRC, Boca Raton, Florida.

578 Woodward, F.I. (2007) An inconvenient truth. New Phytologist, 174, 469-470.

579 Yakir, E., Hilman, D., Harir, Y. \& Green, R.M. (2007) Regulation of output from the plant circadian clock. FEBS Journal, 274, 335-345.

581 Zhang, Q., Manzoni, S., Katul, G., Porporato, A. \& Yang, D. (2014) The hysteretic 


\section{$587 \quad$ Figures}

588 Figure 1: Circadian oscillation in the marginal water cost. The dots (with small SE

589 bars hidden) indicate hourly values of assimilation $\left(A_{\text {net }}\right)$ stomatal conductance $\left(g_{\mathrm{s}}\right)$

590 and a parameter proportional to the marginal water cost of carbon gain $\left(g_{1}\right)$.

591 Measurements were taken concomitantly to those under constant conditions reported

592 in Fig. 2, although data from both days were pooled together to increase sample size.

593 The white and black rectangles at the base indicate the subjective day (when it would

594 have been daytime during entrainment) and subjective night, respectively, under

595 constant conditions. Lines (and shaded error intervals) indicate the prediction (and

596 SE) of Generalized Additive Model (GAM) fitting separately for each species (some

597 lines may overlap), and portions which are not yellow indicate significant temporal 598 variation.

600 Figure 2. Circadian regulation of leaf assimilation $\left(A_{\text {net }}\right)$ over stomatal conductance

$601\left(g_{\mathrm{s}}\right)$. During entrainment, environmental conditions of Temperature $\left(T_{\text {air }}\right)$ and Vapor

602 Pressure Deficit (VPD) mimicked those outdoors, with $500 \mu \mathrm{mol} \mathrm{m}^{-2} \mathrm{~s}^{-1}$ PAR (first 24

$603 \mathrm{~h}$ shown), and remained constant for $48 \mathrm{~h}$ starting at solar noon. The grey and white

604 backgrounds indicates when PAR was at $0\left(\mu \mathrm{mol} \mathrm{m} \mathrm{m}^{-2}\right)$ or higher, respectively.

605 White and black rectangles at the base indicate the subjective day (when it would

606 have been daytime during entrainment) and subjective night, respectively, under

607 constant conditions. Dots represent measured values at each of three replicate

608 macrocosms, and thick lines (and shaded error intervals) indicate the prediction (and

609 SE) of Generalized Additive Mixed Model (GAMM) fitting separately for each

610 species (some lines may overlap). GAMM best-fit line portions which are not yellow

611 indicate significant temporal variation. Values in (b-d) were measured by the different 

available under aCC-BY 4.0 International license.

612 macrocosms every 15 minutes and values in (a) were measured every 4 hours with a

613 portable photosynthesis system (the cuvette was set to match macrocosm conditions).

614 
Table 1: Quantification of the circadian-driven range in variation of diurnal gas

exchange. The variation in fluxes under constant environmental conditions was derived from Generalized Aditive Mixed Model predictions in Fig. 2.

\begin{tabular}{|c|c|c|c|c|}
\hline \multirow[t]{2}{*}{ Process } & \multirow[t]{2}{*}{ Species } & \multicolumn{3}{|c|}{ Variation under constant conditions } \\
\hline & & Maximum & Minimum & $\%$ Change \\
\hline \multirow[t]{2}{*}{$A_{\text {net }}\left(\mu \mathrm{mol} \mathrm{m} \mathrm{m}^{-2} \mathrm{~s}^{-1}\right)$} & P. vulgaris & 15.42 & 11.02 & 28.48 \\
\hline & G. hirsutum & 16.97 & 9.73 & 42.65 \\
\hline \multirow[t]{2}{*}{$g_{\mathrm{s}}\left(\mathrm{mol} \mathrm{m} \mathrm{s}^{-2}\right)$} & P. vulgaris & 0.31 & 0.14 & 54.03 \\
\hline & G. hirsutum & 0.41 & 0.063 & 84.85 \\
\hline Anet/gs $\left(\mu \mathrm{mol} \mathrm{CO} \mathrm{CO}_{2} / \mathrm{mol}\right.$ & P. vulgaris & 95.37 & 51.17 & 46.35 \\
\hline $\left.\mathrm{H}_{2} \mathrm{O}\right)$ & G. hirsutum & 156.23 & 40.52 & 74.06 \\
\hline
\end{tabular}


bioRxiv preprint doi: https://doi org/101101/121368; this version posted June 6, 2017. The copyright holder for this preprint (which was

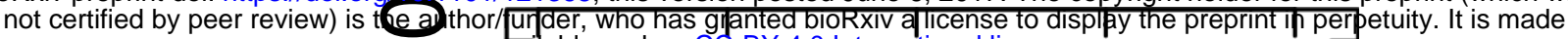

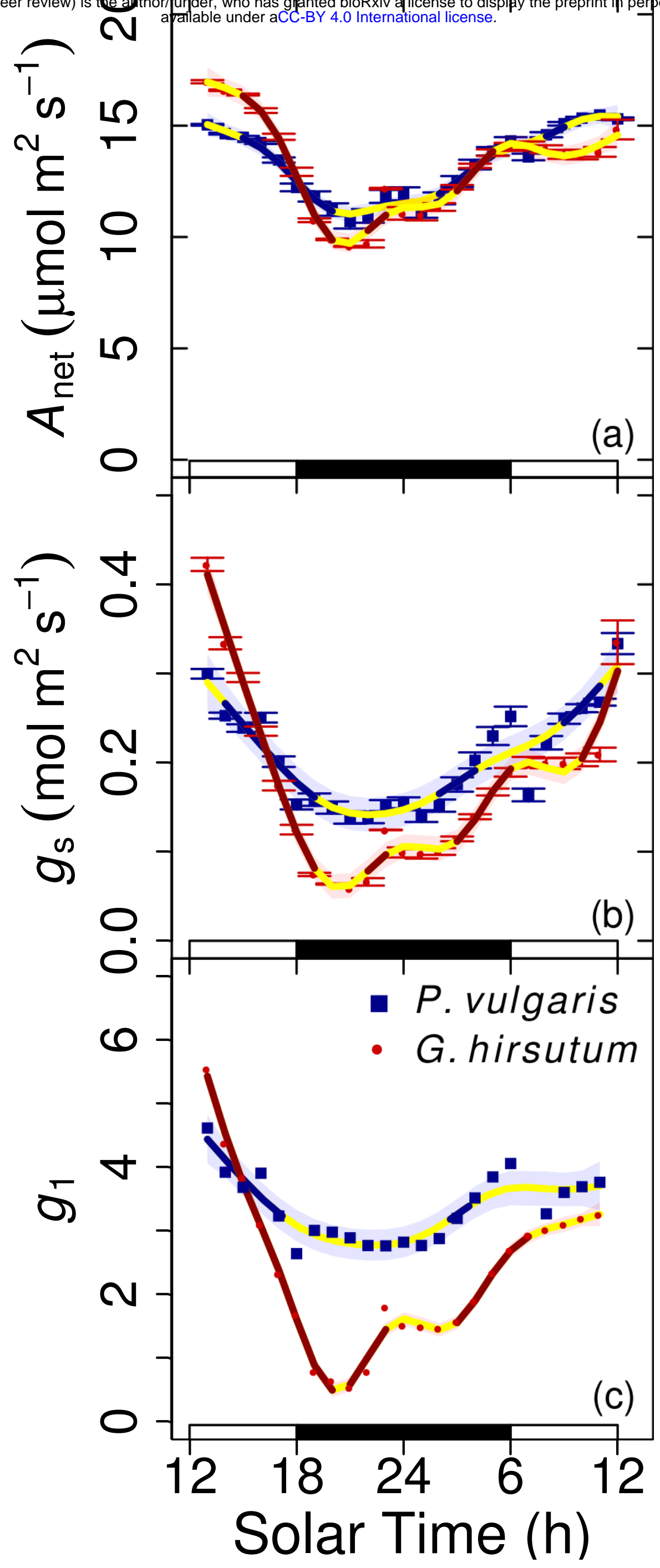


bioRxiv preprint doi: https://doi org/10.1101/121368; this version posted June 6 2017. The copyright holder for this preprint (which was
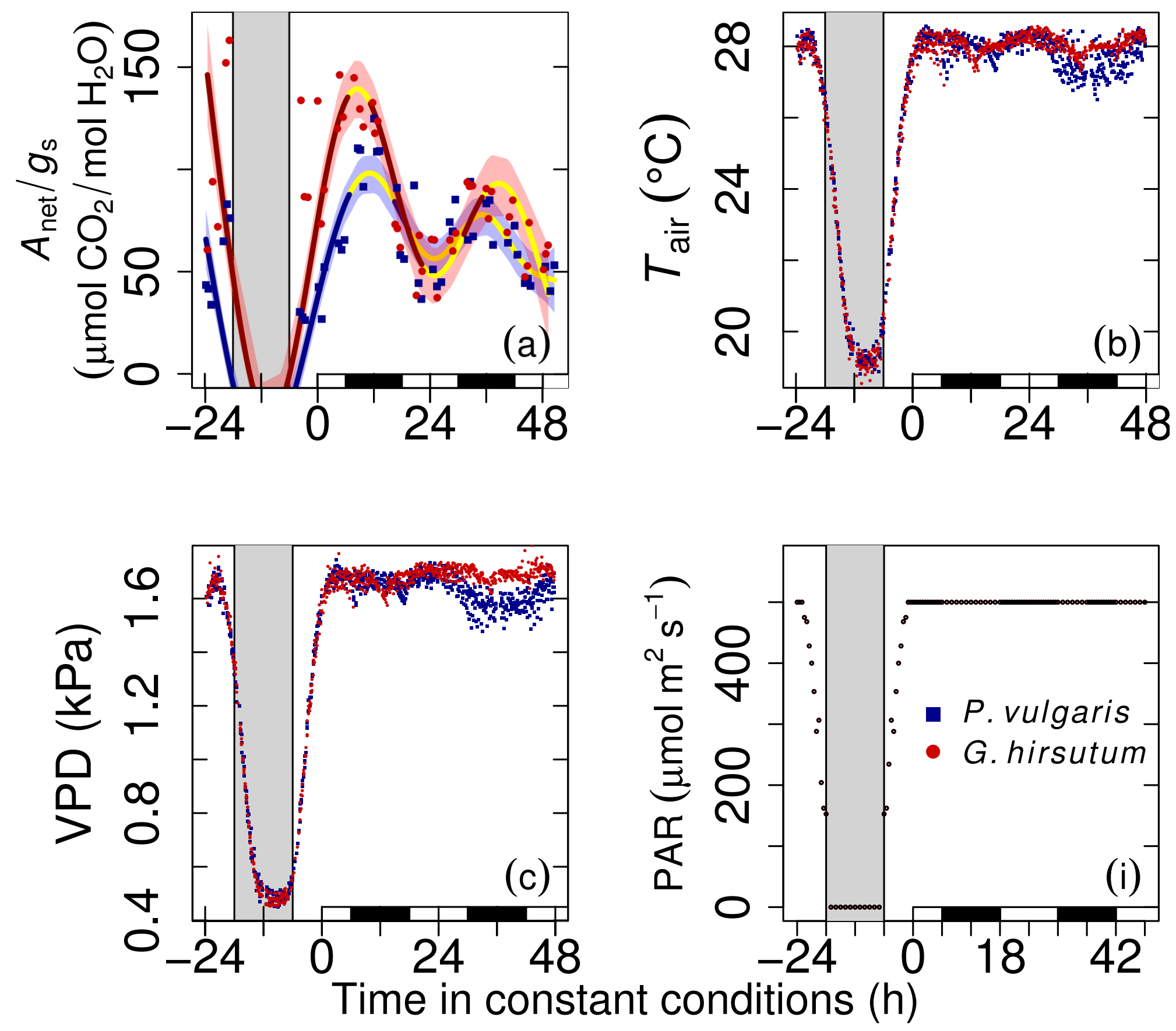